ORIGINAL ARTICLE

\title{
A mutation in the gamma actin 1 (ACTG1) gene causes autosomal dominant hearing loss (DFNA20/26)
}

\author{
E van Wijk, E Krieger, M H Kemperman, E M R De Leenheer, P L M Huygen, C W R J Cremers, \\ F P M Cremers, H Kremer
}

J Med Genet 2003;40:879-884

See end of article for authors' affiliations

.....................

Correspondence to: Dr H Kremer, Department of Otorhinolaryngology, UMC Nijmegen, PO Box 9101, 6500 HB Nijmegen, Netherlands;h.kremer@ antrg.umen.nl

Received 12 July 2003 Accepted 5 September 2003
Linkage analysis in a multigenerational family with autosomal dominant hearing loss yielded a chromosomal localisation of the underlying genetic defect in the DFNA20/26 locus at 17q25-qter. The 6CM critical region harboured the $\gamma$-1-actin (ACTG1) gene, which was considered an attractive candidate gene because actins are important structural elements of the inner ear hair cells. In this study, a Thr278lle mutation was identified in helix 9 of the modelled protein structure. The alteration of residue Thr278 is predicted to have a small but significant effect on the $\gamma 1$ actin structure owing to its close proximity to a methionine residue at position 313 in helix 11 . Met313 has no space in the structure to move away. Moreover, the Thr278 residue is highly conserved throughout eukaryotic evolution. Using a known actin structure the mutation could be predicted to impair actin polymerisation. These findings strongly suggest that the Thr278lle mutation in ACTG1 represents the first disease causing germline mutation in a cytoplasmic actin isoform.
$\mathrm{H}$ ereditary hearing loss is the most common sensorineural deficit and has the highest degree of genetic heterogeneity. So far, 19 genes are known to be involved in autosomal recessive forms of the disorder, 18 in autosomal dominant forms, and two in X linked types. Six of these genes can cause both autosomal dominant and recessive hearing loss. At least 36 genes remain to be identified, based on the number of known genetic loci, 17 of which are implicated in autosomal dominant forms. ${ }^{1}$

Autosomal recessive hearing loss is almost exclusively prelingual, severe to profound, and involves all frequencies. In contrast, autosomal dominant hearing loss shows variation in the type of hearing loss, the age of onset, and the rate of progression (for reviews, see Huygen et $a^{2}$ and Pennings et $\mathrm{al}^{3}$ ). For individual autosomal dominant families it is often possible to suggest one or a few loci or genes that may be involved, through cross sectional or longitudinal analysis of audiograms of several family members. ${ }^{45}$

Four families with autosomal dominant postlingual sensorineural hearing loss were found to be linked to overlapping regions of chromosome 17q25,,$^{6-9}$ and two different DFNA locus numbers (DFNA20 and DFNA26) were assigned to this region. We recently described a fifth Dutch family with linkage to this interval. ${ }^{10}$ Gently downsloping audiograms are seen in individuals at ages below 15 years. The hearing loss progresses to profound at the ages of 15-20 years and 25-40 years for the frequencies of $8 \mathrm{kHz}$ and $1-4 \mathrm{kHz}$, respectively. At frequencies below $1 \mathrm{kHz}$ progression is slower. The hearing loss in this family is very similar to that in the family described by DeWan et al. ${ }^{9}$ Although hearing loss in the original DFNA20 family follows a less severe course, the progression is highest for $8 \mathrm{kHz}$, followed by 4,2 , and $1 \mathrm{kHz} .^{7}$

In this paper we describe candidate gene analysis in the Dutch family, which led to the identification of a missense mutation in the ACTG1 gene which encodes $\gamma$-actin 1. Using the structure of the highly homologous $\mathrm{Mg}^{2+}$-ATP actin 1 of Dictyostelium discoideum, we provide evidence that the missense mutation has a small but significant functional effect. This represents the first description of a probable disease causing germline mutation in a cytoplasmic actin isoform.

\section{METHODS \\ Subjects}

A Dutch family with autosomal dominant hearing loss, W99-060, was ascertained (fig 1). Pure tone audiograms were obtained as described by Kemperman et al. ${ }^{10}$ The study was approved by the local ethics committee, and written informed consent was obtained from each participating individual.

\section{Amplification of the ACTG 1 gene}

DNA was isolated from blood samples using a salting out procedure. ${ }^{11}$ Primers for amplification of exons and exonintron boundaries of the P4HB, MAFG, CARDI4, SLC26Al1, and DKFZp434D1428 genes are available on request. Primers for amplification of the six exons and splice sites of the ACTGI gene were designed using the published genomic sequence (NCBI accession No, M19283). The primers used (Invitrogen), annealing temperatures, and $\mathrm{MgCl}_{2}$ concentrations are listed in table 1. Amplification was done in a PTC200 thermo cycler (MJResearch). Cycling conditions were five minutes denaturation at $95^{\circ} \mathrm{C}$, followed by 30 cycles of 30 seconds at $95^{\circ} \mathrm{C}, 30$ seconds annealing, and one minute elongation at $72^{\circ} \mathrm{C}$.

\section{Sequence analysis}

Polymerase chain reaction (PCR) fragments were purified on Qiaquick spin columns (Qiagen). Sequencing reactions were done with the ABI PRISM Big Dye Terminator cycle sequencing V2.0 ready reaction kit. For the analysis we used the ABI PRISM 3700 DNA analyser (Applied Biosystems). The sequencing primers were the same as those used for amplification of the exons. For sequencing of exon 6 two additional internal primers were synthesised: $5^{\prime}$ TGTACATATCTTTGAGTTC-3' and 5'-CAAGCCACAGACTTGTCTTC-3'.

\section{Amplification-refractory mutation system analysis} Screening of the c.833C $>\mathrm{T}$ mutation in exon 5 in 300 unrelated control individuals was carried out by amplification-refractory mutation system (ARMS) analysis. We 


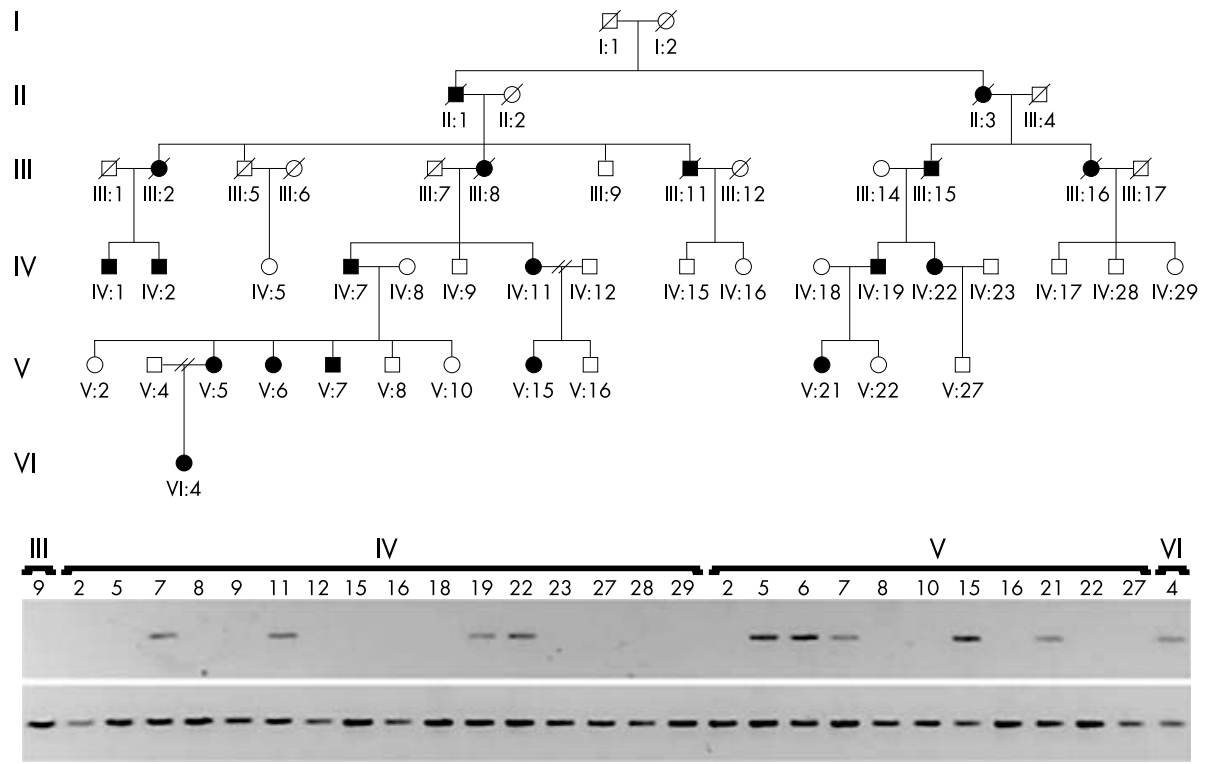

Figure 1 Segregation of the $833 \mathrm{C}>\mathrm{T}$ mutation in the ACTG1 gene in family W99-060. The top gel figure in the lower panel shows the polymerase chain reaction products using the mutant reverse ARMS primer, while the bottom gel figure shows the analysis with the wild-type reverse ARMS primer.

designed ARMS primers for both the wild-type and mutant allele-wild-type reverse primer, 5'-ACGTCACACTTCATGATGGAGTTGAAAG-3'; mutant reverse primer, 5'ACGTCACACTTCATGATGGAGTTGAAAA-3'. As a forward primer, the exon 4 forward primer was used. Amplification was done as described above with an annealing temperature of $58^{\circ} \mathrm{C}$ and an $\mathrm{MgCl}_{2}$ concentration of $2.0 \mathrm{mM}$ on a PTC200 thermo cycler (MJResearch).

\section{Molecular modelling}

The mutation was analysed using the DGMUT command ${ }^{12}$ in WHAT IF. ${ }^{13}$ DGMUT scanned 400 high resolution $x$ ray structures for stretches of five residues with an isoleucine in the middle, which superimpose well on the five residues centred on threonine in the known actin structure (1NMl). For every hit, the isoleucine rotamer was displayed on screen. Especially for large flexible side chains, such an analysis yields a distribution of equally likely rotamers, and energy functions are required to choose the best one. In the case of the Thr278Ile mutation, however, only one possibility was found.

\section{RESULTS}

\section{Genetic analyses}

Recently, the genetic defect causing hearing loss in a Dutch family with dominant progressive hearing loss was localised to the DFNA20/26 region at chromosome $17 \mathrm{q} 25.3$. The critical interval in the present family was between the marker D17S784 and 17qter. ${ }^{10}$ The hearing loss in the family is comparable to that in the family described by DeWan et al, ${ }^{9}$ in which the critical region is flanked by the markers D17S784 and D17S928. In order to identify the causative gene for DFNA20/26, candidate genes were selected from the interval between D17S784 and D17S928 comprising $6 \mathrm{cM}$ (2.4 Mb). This region contains 62 known genes and more than 100 expressed sequence tags (ETS). Causative mutations in the protein coding regions and intron-exon boundaries of the genes P4HB, MAFG, CARD14, SLC26A11, and DKFZp434D1428 were excluded by sequence analyses. Recently, the ACTGI gene encoding $\gamma \mathrm{l}$ actin was relocated in the critical region. ${ }^{14}$ Owing to the important function of actin in hair cell structure, this gene was considered a major candidate and the exons and exon-intron boundaries were amplified for an affected individual (IV:7) and sequenced. Several changes were found when compared with the published sequence of the gene (NCBI accession No, M19283). Eight nucleotide changes were found including the known polymorphism Tyr306Tyr (ENTREZ SNP database 1139405). In exon 1 the c. $-55 \mathrm{G}>\mathrm{A}$ substitution was homozygously present, as was the g.IVS3 $+13 \mathrm{C}>\mathrm{A}$ substitution. The heterozygous changes g.IVS $1+135 \mathrm{C}>\mathrm{T}$, g.IVS $1+151 \mathrm{G}>\mathrm{C}$, and g.IVS2-38C $>\mathrm{T}$ are not located within the splice site consensus sequences, are

Table 1 Primer sequences and conditions for amplification of ACTG 1 exons

\begin{tabular}{|c|c|c|c|}
\hline Primer set & Primer sequence & $\begin{array}{l}\text { Annealing } \\
\text { temperature }\end{array}$ & {$\left[\mathrm{MgCl}_{2}\right]$} \\
\hline $\begin{array}{l}\text { Exon } 1 F \\
\text { Exon } 1 R\end{array}$ & $\begin{array}{l}\text { GCCGCTTCCGCTTAAATAAC } \\
\text { GGCCIIIACGTAACGTCCAC }\end{array}$ & $50^{\circ} \mathrm{C}$ & $2.0 \mathrm{mM}$ \\
\hline $\begin{array}{l}\text { Exon } 2 / 3 F \\
\text { Exon } 2 / 3 R\end{array}$ & $\begin{array}{l}\text { GAGGGGACCGTGTACAGAC } \\
\text { GAAAATGACTGGGGAAAGGAC }\end{array}$ & $55^{\circ} \mathrm{C}$ & $1.5 \mathrm{mM}$ \\
\hline $\begin{array}{l}\text { Exon } 4 \mathrm{~F} \\
\text { Exon } 4 \mathrm{R}\end{array}$ & $\begin{array}{l}\text { TGGGTCTCTGTCCCTGACTAAG } \\
\text { GATGCCGCAAGATCCATAC }\end{array}$ & $55^{\circ} \mathrm{C}$ & $2.5 \mathrm{mM}$ \\
\hline $\begin{array}{l}\text { Exon } 5 F \\
\text { Exon } 5 R\end{array}$ & $\begin{array}{l}\text { CGGTGACACAGCATCACTAAG } \\
\text { ACGGCTICAGCTCACAGAG }\end{array}$ & $55^{\circ} \mathrm{C}$ & $1.5 \mathrm{mM}$ \\
\hline Exon $6 \mathrm{~F}$ & AAGGTGAGTCGAGGGGTTG & $55^{\circ} \mathrm{C}$ & $2.5 \mathrm{mM}$ \\
\hline Exon 6R & ССACTTGCTACTTCCCCAAAC & & \\
\hline
\end{tabular}





Figure 2 Partial sequence of exon 5 in a control individual $(A)$ and patient IV:7 (B). The patient shows a heterozygous ACC $>$ ATC transition causing the Thr278lle substitution.

not predicted to create new splice sites, and are also not located within the branchpoint. ${ }^{15}$ The detected g.IVS5+54 delG does not co-segregate with the disease. In exon 5 the nucleotide transition c.833 C>T was detected. The putative effect of this mutation is the substitution of isoleucine for threonine at position 278 of the protein (Thr278Ile) (fig 2).

An ARMS PCR was developed to test for the presence of the c.833C $>$ T mutation in control individuals and to analyse the segregation of the mutation in the family. The mutation co-segregates with the disease (fig 1) but is not present in individual IV:2 who was already suggested to be a phenocopy by linkage analysis. ${ }^{10}$ The mutation was not present in 300 white controls, of whom 200 were of Dutch origin. Moreover, residue Thr278 is conserved in almost all actin isoforms throughout eukaryotes including yeast (fig 3). These results exclude the mutation being a common polymorphism and suggest that it is causative for the disease.

\section{Molecular modelling}

The effect of the Thr278Ile mutation was investigated using a known actin structure from Dictyostelium discoideum, actin 1 (PDB entry $1 \mathrm{NMl}) .{ }^{16}$ Contrary to known vertebrate actins, this structure was solved at high resolution (1.8 $\mathrm{\AA}$ ), while it is also highly similar to human $\gamma$ actin (95\% sequence identity, fig 3). As the residues around Thr 278 are also conserved, the mutation could be analysed directly in the known structure, without building a model for human actin first. Using WHAT $\mathrm{IF}^{13}$ we found that an isoleucine at position 278 , located in helix 9 (residues 274-282) of the protein, ${ }^{17}$ can adopt only one possible side chain conformation or rotamer (fig 4). In this conformation, its $\delta$ carbon comes within $2.4 \AA$ of the $\epsilon$ carbon of methionine 313 in helix 11 (residues 309-320). This is $1.4 \AA$ shorter than the sum of the Van der Waals radii. Owing to the tight packing inside the hydrophobic core, Met313 has no space to move away from this strong clash. It has been shown that clashes of this type often lead to reorganisation of entire secondary structure elements, ${ }^{18}$ in this case helices 9 and 11. A movement of either helix is likely to affect actin polymerisation: helix 9 provides structural support for the hydrophobic loop 262-274 which was shown to be involved in polymerisation, ${ }^{19}$ while helix 11 is attached to the ATP binding P3 loop. ${ }^{16}$

Additional evidence that the Thr278Ile mutation cannot be accommodated without affecting the function comes from another member of the actin multigene family in $D$ discoideum (Swissprot accession No, P07828): this protein actually has an isoleucine at position 278, which is compensated by a Thr162Ala exchange that creates the space required by the additional methyl group in Ile 278. In the mutant reported here, this space is not available.

\section{DISCUSSION}

We have shown here that the c.833C $>$ T mutation in the gene encoding cytoplasmic $\gamma$-1-actin (ACTGI) is involved in dominant sensorineural hearing loss DFNA20/26. The c. $833 \mathrm{C}>\mathrm{T}$ mutation in ACTG1 is the first germline mutation described in a cytoplasmic actin leading to disease.

The absence of the nucleotide change in 300 control individuals, together with structural analysis, indicates that

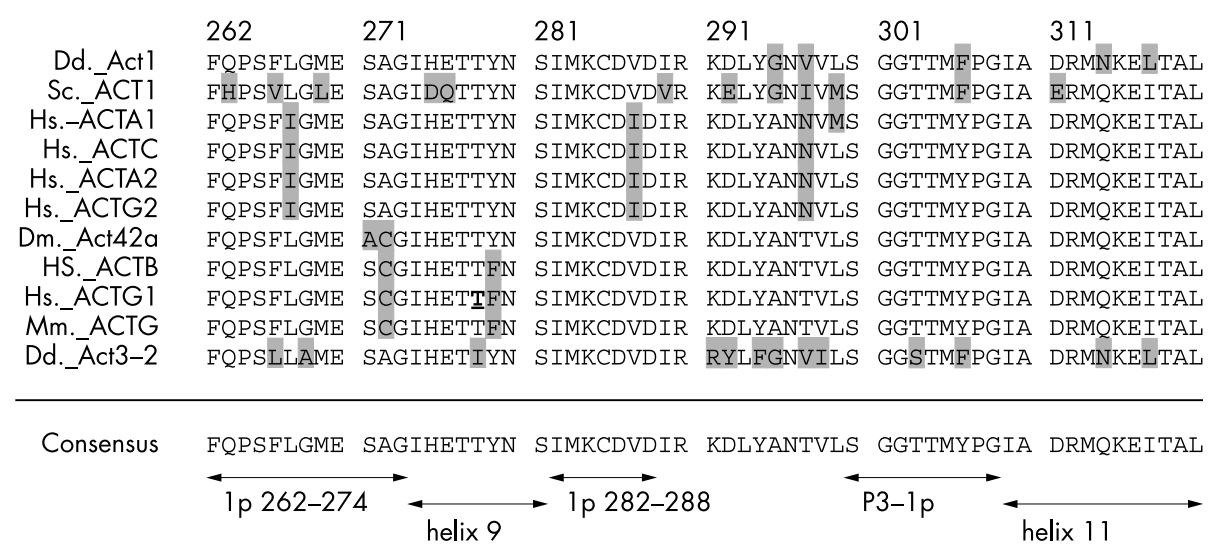

Figure 3 Multiple alignment of all known human ( $\mathrm{Hs}$ ) actin genes, cytoplasmic actin of yeast ( $\mathrm{Sc}$ ), Drosophila (Dm), and mouse (Mm), and Actl of $D$ discoideum (Dd) which was used for modelling the 833C $>$ T mutation. Thr278 in ACTG1 is underlined and marked (bold). Double headed arrows below the consensus sequence indicate the corresponding regions of loop 262-274, loop 282-288, helix 9, the P3 loop, and helix 11 . Shaded residues differ from the consensus sequence. The Swiss Prot accession numbers of the genes from top to bottom are P02577, BAA21512, P02568, P04270, P03996, P12718, P02572, P02570, P02571, NP033739, and P07828. 


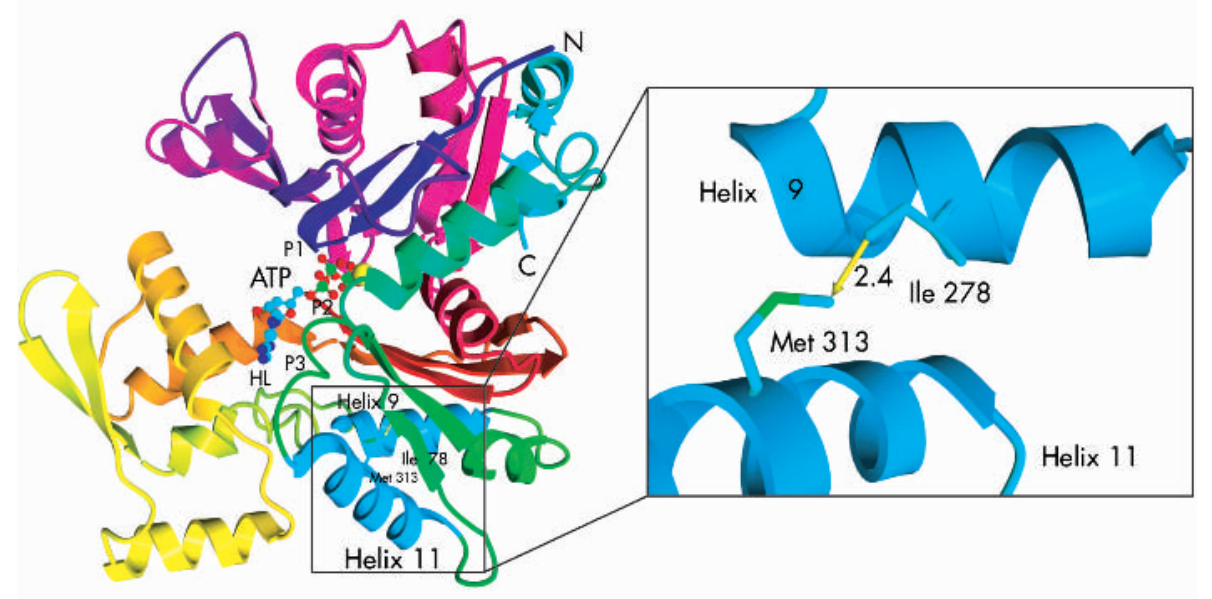

Figure 4 Structure of actin from D discoideum. The protein is coloured with a gradient from blue ( $\mathrm{N}$-terminus) to cyan (C-terminus), except for helices 9 and 11 , which are shown in light blue. The three ATP binding loops (P1 to P3) and the hydrophobic loop involved in polymerisation (HL) are marked. At position 278, the predicted side chain conformation of the isoleucine mutant is indicated, causing a strong bump with Met 313 (distance is $2.4 \AA$ ). The image was created with YASARA (www.yasara.org).

the change is the disease causing mutation. Mutation analysis in four additional families linked to the DFNA20/ 26 locus might reveal additional mutations in the ACTG1 gene, thereby providing definite proof for ACTGI as a hearing loss gene. Alternatively, this analysis might point towards a second gene in the region.

Actins are ubiquitous proteins in eukaryotes and are involved in diverse cellular functions including muscle contraction, cell motility, cell adhesion, and cell shape. ${ }^{20}$ In vertebrates, six different isoforms-three $\alpha$, one $\beta$, and two $\gamma$-are distinguished. The $\alpha$ isoforms and one $\gamma$ isoform are muscle specific. The $\beta$ and $\gamma$ isoforms are the non-muscle cytoplasmic isoforms. ${ }^{21}$ Actin monomers (G-actin) polymerise to form filaments (F-actin). The affected residue Thr278 is invariant in all human actin isoforms and is highly conserved in other eukaryotes. By using a known actin structure, the effect of the amino acid substitution can be predicted to cause a reorganisation of the helices 9 and 11 in subdomain III of the actin molecule owing to an increase in size of the side chain at position 278 in the protein. Helix 11 is attached to the P3 loop containing residues 302-308 that form one side of the adenine pocket ${ }^{22}$ (reviewed by Hennessey et $a^{23}$ ).

Because actin monomers are stabilised by ATP binding under physiological conditions and unbound actin is rapidly degraded, ${ }^{24}$ impairment of ATP binding by the Thr278Ile mutation might lead to a reduced availability of G-actin for polymerisation into filaments. Helix 9 is attached at its $\mathrm{N}$ terminal side to loop 262-274, which has been shown to play a critical role in polymerisation of actin into filaments. ${ }^{19}$ At its C-terminal side helix 9 is attached to loop 282-288. Residues in this loop make close contact with profilin, an actin monomer binding protein that facilitates the addition of these monomers to the plus end of F-actin. ${ }^{25}$ Reorganisation of these loops because of the Thr278Ile mutation can therefore be predicted to influence actin polymerisation. In addition to the localised effects, the mutation might have long range effects on the structure of other regions of the actin molecule as is shown for other amino acid substitutions in actin by Drummond et al. ${ }^{26}$

The consequences of this type of effect for actin function are difficult to predict. That the Thr278Ile mutation leads to function impairment is supported by studies on actin mutated in either helix 9 or helix 11 . The Arg312His mutation in the cardiac actin gene ACTC is causative for dominantly inherited dilated cardiomyopathy. ${ }^{27}$ The Arg312Ala mutation in yeast ACT1 leads to reduced viability, ${ }^{23}$ and the Glu316Lys mutation in the Drosophila Act88F actin leads to reduced stability of the protein in vitro, muscles with slightly disrupted ultrastructure, and altered kinetics of force generation by muscle fibres. ${ }^{28}{ }^{29}$ Glu316 forms hydrogen bonds with residues 312 and 275 (helix 9). ${ }^{29}$ The amino acid substitution Asn280Lys in human ACTAl leads to dominant nemaline myopathy. ${ }^{30}$

Although cytoplasmic $\beta$ and $\gamma$ actins are ubiquitously expressed, the only symptom in the present family is sensorineural hearing loss. This points towards actin based structures specific for the inner ear as the site of the defect. The most conspicuous cochlear structures containing actin filaments are in the hair cells. They include the stereocilia, which contain a rigid dense core of actin filaments, the cuticular plate into which stereocilia are anchored, consisting of a gel-like actin network, and a ring of parallel actin filaments connected to the zonula adherens. ${ }^{31}$ Although $\beta$ actin is the predominant cytoskeletal isoform in several mouse tissues, ${ }^{32}$ in chicken auditory hair cells $\gamma$ actin is the predominant actin isoform, present in all three conspicuous actin based structures. ${ }^{21} \beta$ Actin is specifically sorted to the actin core filament bundles of the stereocilia. ${ }^{21}$ The actin filaments of the stereocilia core are continuously renewed at the tip through the addition of G-actin. The filament bundles "treadmill" towards the base of the stereocilia. ${ }^{33}$ This process might be disturbed by a reduced amount of available G-actin. This would imply that the mutation results in haploinsufficiency. Impaired polymerisation through a rearrangement of the loops 262-274 and 282-288 might also affect the process of filament renewal in stereocilia. Whether the cuticular plate and the zonula adherens belt are subject to a comparable fast renewal of actin filaments remains to be determined.

Besides an effect on stability or incorporation of the mutated actin monomers in filaments, the mutation also might have an effect through a subtle change in the structure of the molecule. Upon incorporation of mutant G-actin into a filament, this structural change might lead to functional impairment of the whole filament. Such dominant negative effects are shown to be caused by mutated subunits in collagen fibres and keratin filaments. ${ }^{34} 35$

The hearing loss in the present family shows a very rapid progression. Deterioration is almost complete within the first three decades of life. ${ }^{10}$ The high frequencies are clearly affected most within these first three decades, which might 
be explained by the fact that the rigidity of the stereocilia is highest in the basal region of the cochlea ${ }^{31}$ and therefore will suffer most from impaired stereocilia structure. The highly progressive nature of the hearing loss suggests that initially the affected structures are functioning normally but that over several decades a combination of a disbalanced renewal of actin filaments and the effects of aging lead to an early deterioration of the system. Progressive retinitis pigmentosa in patients with Usher syndrome caused by myosin VIIa (MYO7A) mutations might well be an example of the same type of pathogenesis. Photoreceptor disks are constantly renewed and this process is affected by MYO7A mutations. ${ }^{36}$

It is noteworthy that the causative genes in the three other known types of dominant sensorineural hearing loss with rapid progression in the first three decades of life (DFNAl, DFNA17, and DFNA22) encode proteins that are functionally related to actin (diaphanous, non-muscle myosin heavy chain A and myosin VI). ${ }^{37-39}$ The diaphanous gene (DFNAl), for example, plays a role in the regulation of actin polymerisation. $^{40}$

Audiograms in the present DFNA20/26 patients from about 30 years of age onwards are reminiscent of the hearing loss in (young) patients with USHl. ${ }^{41}$ Mouse models for the causative genes for USHl, myosin VIIA (MYO7A), cadherin 23 (CDH23), protocadherin 15 (PCDH15), and SANS show disorganised hair bundles (reviewed by Ahmed et $a l^{42}$ ). Several histological and biochemical studies indicate that these proteins-together with the F-actin bundling protein harmonin, mutated in USHIC-are part of a functional complex anchored to the actin core of stereocilia and responsible for the cohesion of these hair cell protrusions. ${ }^{43-45}$ The similarities observed between DFNA20/26 and the above mentioned non-syndromic and syndromic types of hearing loss support the hypothesis that the Thr278Ile mutation in $\gamma$ actin 1 leads to stereocilial dysfunction. Our data suggest that the gene encoding $\beta$ actin is a good candidate for hereditary hearing loss.

\section{ACKNOWLEDGEMENTS}

We are grateful to the members of the family for participating in this study. The study was supported by ZON-MW (project No 920-03100), the Heinsius Houbolt Foundation, and the Nijmegen ORL Research Fund.

\section{Authors' affiliations}

E van Wijk, M H Kemperman, E M R De Leenheer, P L M Huygen, C W R J Cremers, H Kremer, Department of Otorhinolaryngology, University Medical Centre, Nijmegen, Netherlands

E Krieger, Centre for Molecular and Biomolecular Informatics, University of Nijmegen

F P M Cremers, Department of Human Genetics, University Medical Centre Niimegen

E M R De Leenheer, Department of Otorhinolaryngology, Head and Neck surgery, Ghent University Hospital, Ghent, Belgium

\section{REFERENCES}

1 Van Camp G, Smith RJH. Hereditary hearing loss homepage. http://dnalabwww.uia.ac.be/dnalab/hhh/, June, 2003.

2 Huygen PLM, Pennings RJE, Cremers CWRJ. Characterizing and distinguishing progressive phenotypes in nonsyndromic autosomal dominant hearing impairment. Audiol Med 2003; 1:37-46.

3 Pennings RJE, Huygen PLM, Van Camp G, Cremers CWRJ. A review of progressive phenotypes in nonsyndromic autosomal dominant hearing impairment. Audiol Med 2003:1:47-55.

4 Lesperance MM, Hall JW, San Agustin TB, Leal SM. Mutations in the Wolfram syndrome type 1 gene (WFS1) define a clinical entity of dominant lowfrequency sensorineural hearing loss. Arch Otolaryngol Head Neck Surg 2003:129:411-20.

5 Bischoff AMLC, Luijendijk MWJ, Huygen PLM, Van Duijnhoven G, De Leenheer EMR, Oudesluijs G, Van Laer L, Cremers FPM, Cremers CWR Kremer $\mathrm{H}$. A novel mutation identified in the DFNA5 gene in a Dutch family. A clinical and genetic evaluation. Audiol Neurootol (in press).
6 Morell RJ, Friderici $\mathrm{KH}$, Wei S, Elfenbein JL, Friedman TB, Fisher RA. A new locus for late-onset, progressive, hereditary hearing loss DFNA20 maps to 17q25. Genomics 2000;63:1-6.

7 Elfenbein JL, Fisher RA, Wei S, Morell RJ, Stewart C, Friedman TB, Friderici K. Audiologic aspects of the search for DFNA20: a gene causing late-onset progressive, sensorineural hearing loss. Ear Hear 2001;22:279-88.

8 Yang T, Smith R. A novel locus DFNA 26 maps to chromosome 17q25 in two unrelated families with progressive autosomal dominant hearing loss. Am J Hum Genet 2000;67(suppl 2):300.

9 DeWan AT, Parrado AR, Leal SM. A second kindred linked to DFNA20 (17q25.3) reduces the genetic interval. Clin Genet 2003;63:39-45.

10 Kemperman MH, De Leenheer EMR, Huygen PLM, Van Wijk E, Van Duijnhoven G, Cremers FPM, Kremer H, Cremers CWRJ. A Dutch family linked to the DFNA20/26 locus. Longitudinal analysis of hearing impairment. Arch Otolaryngol Head Neck Surg (in press).

11 Miller SA, Dykes DD, Polesky HF. A simple salting out procedure for extracting DNA from human nucleated cells. Nucleic Acids Res 1988;16:1215.

12 Chinea G, Padron G, Hooft RW, Sander C, Vriend G. The use of positionspecific rotamers in model building by homology. Proteins 1995;22:415-21.

13 Vriend G. WHAT IF: a molecular modeling and drug design program. J Mol Graph 1990;8:52-6.

14 UCSC Genome Browser. 2003. http://genome.cse.ucsc.edu/ Release April, 2003.

15 Shapiro MB, Senapathy P. RNA splice junctions of different classes of eukaryotes: sequence statistics and functional implications in gene expression. Nucleic Acids Res 1987:15:7155-74.

16 Vorobiev S, Strokopytov B, Drubin DG, Frieden C, Ono S, Condeelis J, Rubenstein PA, Almo SC. The structure of nonvertebrate actin: implications for the ATP hydrolytic mechanism. Proc Natl Acad Sci USA 2003;100:5760-5

17 Kabsch W, Mannherz HG, Suck D, Pai EF, Holmes KC. Atomic structure of the actin:DNase I complex. Nature 1990;347:37-44.

18 De Filippis V, Sander C, Vriend G. Predicting local structural changes that result from point mutations. Protein Eng 1994;7:1203-8.

19 Shvetsov A, Musib R, Phillips M, Rubenstein PA, Reisler E. Locking the hydrophobic loop 262-274 to G-actin surface by a disulfide bridge prevents filament formation. Biochemistry 2002;41:10787-93.

20 Pollard TD, Cooper JA. Actin and actin-binding proteins. A critical evaluation of mechanisms and functions. Annu Rev Biochem 1986:55:987-1035.

21 Höfer D, Ness W, Drenckhahn D. Sorting of actin isoforms in chicken auditory hair cells. J Cell Sci 1997;110:765-70.

22 Okamoto H, Hiromi Y, Ishikawa E, Yamada T, Isoda K, Maekawa H, Hotta Y. Molecular characterization of mutant actin genes which induce heat shock proteins in Drosophila flight muscles. EMBO J 1986;5:589-96.

23 Hennessey ES, Drummond DR, Sparrow JC. Molecular genetics of actin function. Biochem J 1993;291:657-71.

24 De La Cruz EM, Pollard TD. Nucleotide-free actin: stabilization by sucrose and nucleotide binding kinetics. Biochemistry 1995;34:5452-61.

25 Sheterline P, Clayton J, Sparrow J. Actin. Oxford: Oxford University Press, 1998.

26 Drummond DR, Hennessey ES, Sparrow JC. The binding of mutant actins to profilin, ATP and DNase I. Eur J Biochem 1992;209:171-9.

27 Olson TM, Michels VV, Thibodeau SN, Tai YS, Keating MT. Actin mutations in dilated cardiomyopathy, a heritable form of heart failure. Science 1998;280:750-2.

28 Drummond DR, Peckham M, Sparrow JC, White DC. Alteration in crossbridge kinetics caused by mutations in actin. Nature 1990;348:440-2.

29 Drummond DR, Hennessey ES, Sparrow JC. Characterisation of missense mutations in the Act88F gene of Drosophila melanogaster. Mol Gen Genet $1991 ; 226: 70-80$

30 Nowak KJ, Wattanasirichaigoon D, Goebel HH, Wilce M, Pelin K, Donner K, Jacob RL, Hubner C, Oexle K, Anderson JR, Verity CM, North KN, lannaccone ST, Muller CR, Nurnberg P, Muntoni F, Sewry C, Hughes I, Sutphen R, Lacson AG, Swoboda KJ, Vigneron J, Wallgren-Pettersson C, Beggs AH, Laing NG. Mutations in the skeletal muscle alpha-actin gene in patients with actin myopathy and nemaline myopathy. Nat Genet 1999:23:208-12.

31 Slepecky NB. Structure of the mammalian cochlea. In: Dallos P, Popper AN, Fay RR, eds. The cochlea. New York: Springer-Verlag, 1996:44-129.

32 Erba HP, Eddy R, Shows T, Kedes L, Gunning P. Structure, chromosome location, and expression of the human gamma-actin gene: differential evolution, location, and expression of the cytoskeletal beta- and gamma-actin genes. Mol Cell Biol 1988;8:1775-89.

33 Schneider ME, Belyantseva IA, Azevedo RB, Kachar B. Rapid renewal of auditory hair bundles. Nature 2002:418:837-8

34 Byers PH. Collagens: building blocks at the end of the development line. Clin Genet 2000;58:270-9.

35 Smith F. The molecular genetics of keratin disorders. Am J Clin Dermatol 2003:4:347-64

36 Liu X, Udovichenko IP, Brown SD, Steel KP, Williams DS. Myosin Vlla participates in opsin transport through the photoreceptor cilium. J Neurosci 1999; 19:6267-74.

37 Lynch ED, Lee MK, Morrow JE, Welcsh PL, Leon PE, King MC. Nonsyndromic deafness DFNA1 associated with mutation of a human homolog of the Drosophila gene diaphanous. Science 1997:278:1315-18.

38 Lalwani AK, Goldstein JA, Kelley MJ, Luxford W, Castelein CM, Mhatre AN. Human nonsyndromic hereditary deafness DFNA17 is due to a mutation in nonmuscle myosin MYH9. Am J Hum Genet 2000;67:1121-8.

39 Melchionda S, Ahituv N, Bisceglia L, Sobe T, Glaser F, Rabionet R, Arbones ML, Notarangelo A, Di lorio E, Carella M, Zelante L, Estivill X, 
Avraham KB, Gasparini P. MYO6, the human homologue of the gene responsible for deafness in Snell's waltzer mice, is mutated in autosomal dominant nonsyndromic hearing loss. Am J Hum Genet 2001;69:635-40.

40 Wasserman S. FH proteins as cytoskeletal organizers. Trends Cell Biol 1998:8:111-15.

41 Wagenaar M, van Aarem A, Huygen P, Pieke-Dahl S, Kimberling W, Cremers $C$. Hearing impairment related to age in Usher syndrome types 1B and 2A. Arch Otolaryngol Head Neck Surg 1999;125:441-5.

42 Ahmed ZM, Riazuddin S, Riazuddin S, Wilcox ER. The molecular genetics of Usher syndrome. Clin Genet 2003:63:431-44.

43 Siemens J, Kazmierczak P, Reynolds A, Sticker M, Littlewood-Evans A, Muller U. The Usher syndrome proteins cadherin 23 and harmonin form a complex by means of PDZ-domain interactions. Proc Natl Acad Sci USA 2002;99:14946-51.

44 Weil D, El Amraoui A, Masmoudi S, Mustapha M, Kikkawa Y, Laine S, Delmaghani S, Adato A, Nadifi S, Zina ZB, Hamel C, Gal A, Ayadi H, Yonekawa H, Petit C. Usher syndrome type I G (USHIG) is caused by mutations in the gene encoding SANS, a protein that associates with the USHIC protein, harmonin. Hum Mol Genet 2003;12:463-471.

45 Boëda B, El Amraoui A, Bahloul A, Goodyear R, Daviet L, Blanchard S, Perfettini I, Fath KR, Shorte $S$, Reiners J, Houdusse A, Legrain P, Wolfrum U, Richardson G, Petit C. Myosin Vlla, harmonin and cadherin 23, three Usher I gene products that cooperate to shape the sensory hair cell bundle. EMBO J 2002;21:6689-99.

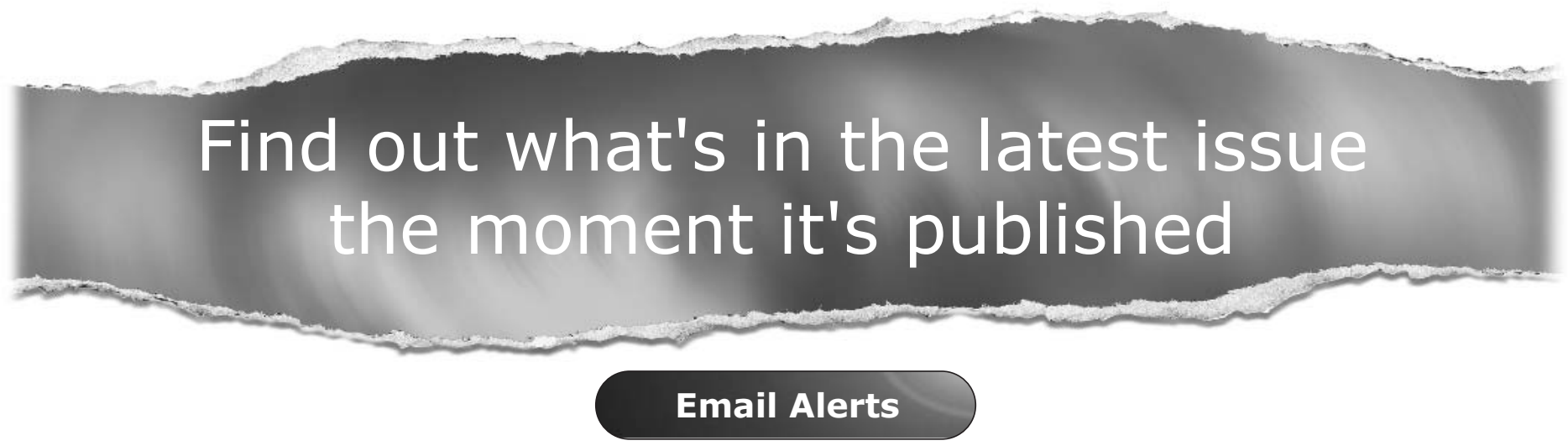

Sign up to receive the table of contents by email every month. You can select from three alerts: Table of Contents (full), TOC Awareness (notice only); Journal of Medical Genetics related announcements.

www.jmedgenet.com 